Annuaire suisse de politique de développement

2| 1982

Annuaire Suisse - Tiers Monde 1982

\title{
Swisscontact : un autoportrait
}

Swisscontact : Eine Selbstdarstellung

Robert Jenny

\section{OpenEdition}

\section{Journals}

Édition électronique

URL : http://journals.openedition.org/aspd/1137

DOI : $10.4000 /$ aspd. 1137

ISSN : 1663-9669

\section{Éditeur}

Institut de hautes études internationales et du développement

\section{Édition imprimée}

Date de publication : 31 août 1982

Pagination : 147-153

ISSN : 1660-5934

\section{Référence électronique}

Robert Jenny, "Swisscontact : un autoportrait », Annuaire suisse de politique de développement [En ligne], 2 | 1982, mis en ligne le 27 janvier 2013, consulté le 08 septembre 2020. URL : http:// journals.openedition.org/aspd/1137; DOI : https://doi.org/10.4000/aspd.1137

Ce document a été généré automatiquement le 8 septembre 2020

(c) The Graduate Institute I Geneva 


\title{
Swisscontact : un autoportrait
}

\author{
Swisscontact : Eine Selbstdarstellung
}

\section{Robert Jenny}

\section{NOTE DE L'ÉDITEUR}

En français, résumé seulement. Lire l'article original en allemand dans Schweizerisches Jahrbuch für Entwicklungspolitik : « Swisscontact : Eine Selbstdarstellung », http:// sjep.revues.org/951.

\section{RÉSUMÉS}

Swisscontact a été créé en 1959 sur l'initiative du Professeur Jacques Freymond, sous la forme d'une Fondation suisse pour l'aide technique au développement. On espérait alors créer une classe moyenne de professionnels capables de prendre en main le développement de leur pays. Les subventions de l'industrie privée ont représenté au total, de 1959 à 1981, la somme de trente millions de francs. Depuis 1964, la Confédération participe également au financement; en 1981, sa part représentait environ $45 \%$ du budget.

Swisscontact est actif dans les domaines suivants: direction et organisation de cycles d'apprentissage technique, formation d'instructeurs, formation de techniciens, organisation de stages et de cours de recyclage, collaboration technique avec des coopératives, appui aux petites entreprises, résolution de problèmes techniques spécifiques par l'envoi d'experts du SEC (Senior Expert Corps). Swisscontact s'adresse principalement à un public déjà éduqué et qui veut poursuivre sa formation, donc à la classe moyenne, tout en admettant des priorités plus immédiates, confiées à d'autres organisations.

Les projets de formation dirigés par Swisscontact doivent être normalement confiés dans leur 
dernière phase à l'entière responsabilité des responsables locaux. Les partenaires sont en règle générale soit l'Etat, soit des organisations contrôlées au moins en partie par l'Etat. L'appui qu'offre l'économie privée à Swisscontact n'est pas lié à des intérêts commerciaux directs, quoique les avantages économiques qui peuvent découler des relations établies ne soient pas considérés comme néfastes. L'adaptation aux besoins des PVD amènera sans doute Swisscontact à devoir réviser ses critères de qualité. Le cas de l'Indonésie montre qu'il faut savoir trouver des compromis avec la quantité.

\section{AUTEUR}

\section{ROBERT JENNY}

Geschäftsleiter von Swisscontact 